\title{
Accuracy of reported service use in a cohort of people who are chronically homeless and seriously mentally ill
}

\author{
Julian M. Somers ${ }^{*}$, Akm Moniruzzaman, Lauren Currie, Stefanie N. Rezansoff, Angela Russolillo and Milad Parpouchi
}

\begin{abstract}
Background: Self-reported service use is an integral feature of interventional research with people who are homeless and mentally ill. The objective of this study was to investigate the accuracy of self-reported involvement with major categories of publicly funded services (health, justice, social welfare) within this sub-population.

Methods: Measures were administered pre-randomization in two randomized controlled trials, using timeline follow back with calendar aids for Health, Social, and Justice Service Use, compared to linked administrative data. Variables examined were: psychiatric admissions (both extended stays of more than 6 months and two or more stays within 5 years); emergency department visits, general hospitalization and jail in the past 6 months; and income assistance in the past 1 month. Participants $(n=433)$ met criteria for homelessness and a least one mental illness.
\end{abstract}

Results: Prevalence adjusted and bias adjusted kappa (PABAK) values ranged between moderate and almost perfect for extended psychiatric hospital separations (PABAK: 0.77; $95 \%$ confidence interval $(C \mathrm{l})=0.71,0.83$ ), multiple psychiatric hospitalizations (PABAK $=0.50,95 \% \mathrm{Cl}=0.41,0.59$ ), emergency department visits (PABAK: $0.77 ; 95$ $\% \mathrm{Cl}=0.71,0.83$ ), jail (PABAK: 0.74; $95 \% \mathrm{Cl}=0.68,0.81$ ), and income assistance (PABAK: $0.82 ; 95 \% \mathrm{Cl}=0.76,0.87$ ). Significant differences in under versus over reporting were also found.

Conclusions: People who are homeless and mentally ill reliably reported their overall use of health, justice, and income assistance services. Evidence of under-reporting and over-reporting of certain variables has implications for specific research questions.

ISRCTN registry: 57595077 (Vancouver at Home Study: Housing First plus Assertive Community Treatment versus congregate housing plus supports versus treatment as usual); and 66721740 (Vancouver at Home study: Housing First plus Intensive Case management versus treatment as usual).

\section{Background}

Individuals who are both mentally ill and homeless are a major health policy focus internationally $[1,2]$. Several multi-site randomized controlled trials have been mounted, with overlapping objectives that include diversion from health and justice services and reductions in the associated costs among samples defined by chronic homelessness and serious mental illness [3-5]. Self reported service involvement is commonly used as the basis for research ranging from national surveys [6] to the aforementioned experimental designs, and the

\footnotetext{
* Correspondence: jsomers@sfu.ca

Somers Research Group, Faculty of Health Sciences, Simon Fraser University, Burnaby, Canada
}

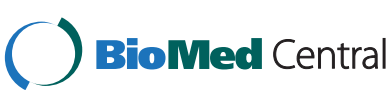

resulting data are used to determine costs of care [7] as well as intervention outcomes.

Although some research has investigated the accuracy of self-reports among people who are either mentally ill [8] or homeless [9], few studies have examined the validity of self-reported service use in samples that are both homeless and seriously mentally ill. Moreover, previous research investigating validity of self-report in this population has used key informant responses as the comparator [10] rather than administrative sources. Research on shelter using veterans in the United States found only "moderate" concordance between self-reported and administrative data, leading the authors to recommend greater reliance on administrative records in research [11]. An earlier 
study among "skid row alcoholics" concluded that the unreliability of self-reports undermined the validity of research investigating employment, arrests, and treatment outcomes in this population [12]. More recently Clifasefi and colleagues [13] investigated the validity of selfreported public health utilization among chronically homeless individuals with severe alcohol problems and found fair-moderate agreement with administrative data for shorter (30 day) periods but inadequate agreement for longer (3 years) timeframes. Several recent studies with homeless and mentally ill adults examine self-reported events spanning up to 5 years $[3,4,14]$.

The validity of self-reported information concerning service encounters may be compromised due to the severity of mental illness [15], or to common correlates of homelessness such as cognitive impairment [16] or substance use [17]. Moreover, questions concerning frequently used services may span several sectors including health, justice, and social assistance, with potential differences in social desirability or risks associated with disclosure [18]. For example, homeless and uninsured individuals are sometimes perceived as contributing to excessive emergency department visits [19], creating a negative bias. Jail and criminal charges may have an adverse impact on access to healthcare [20] as well as housing and support services. Furthermore, the validity of recall for events longer than 6 months previous may be particularly low [16]. Rosen and colleagues [15] compared self-reported receipt of social security income with administrative data for 7220 homeless people with mental disorders and found that $41 \%$ of those who reported receiving benefits were unconfirmed by administrative sources. Moreover, the authors found that self-reported income assistance was more likely to be unverified among clients with psychotic disorders and longstanding substance use. These findings raise important questions regarding the use of self-reported service encounters for the purposes of calculating intervention outcomes as well as for identifying service priorities and gaps in care for members of a highly vulnerable population.

The use of administrative data as a gold standard measure of service use is often unwarranted, as these databases may be subject to inaccuracy and incompleteness [21, 22]. However, in settings with robust and centralized health and social welfare systems, administrative data systems reflect relatively complete records of services, and can be used to assess the validity of self-reports $[22,23]$.

\section{Aims of the study}

The present study examined agreement between selfreported and administrative data for healthcare, corrections, and income assistance in a sample of homeless and severely mentally ill individuals. We hypothesized that agreement regarding hospital admissions would be lower for longer periods of recall than for shorter periods and that jail and emergency department visits would be under-reported due to low social desirability.

\section{Methods \\ Participants \\ Ethics, consent and permissions}

This study was reviewed and approved by the Research Ethics Board at Simon Fraser University. Participants were enrolled in the Vancouver at Home Study, which is comprised of two randomized controlled trials, ISRCTN registry: 57595077 (Vancouver at Home Study: Housing First plus Assertive Community Treatment versus congregate housing plus supports versus treatment as usual) and 66721740 (Vancouver at Home Study: Housing First plus Intensive Case management versus treatment as usual).

\section{Consent to publish}

Participants provided consent for the dissemination of results, and were asked to provide separate consent for investigators to receive administrative records from agencies responsible for health, justice, and social welfare services.

The present study exclusively examined data collected prior to randomization. Eligibility criteria included legal adult status (19 years of age or older), presence of a current mental disorder on the MINI International Neuropsychiatric Interview ([24]; MINI) and being absolutely homeless or precariously housed. Mental disorder status was confirmed through written diagnosis from physicians or other service providers wherever possible. We defined "absolutely homeless" as living on the streets or in a shelter for at least the past seven nights with little chance of obtaining secure accommodation, and "precariously housed" as living in a rooming house, hotel or other form of transitional housing with at least two episodes of absolute homelessness in the past year.

Recruitment of participants involved close collaboration with over 40 community-based agencies in Vancouver. Among those, the major sources of recruitment were: homeless shelters; drop-in centers; homeless outreach teams; hospitals; community mental health teams and criminal justice programs. Methodological details not included in the current study such as additional interviews and measures have been published separately [14].

Participants were invited to complete an eligibility screener as well as written informed consent prior to enrolment in the study. Our protocol for conducting informed consent was developed through pre-trial fieldtesting, including cognitive interviewing to ensure participant comprehension [25]. Interviews were discontinued if participants' mental status appeared to be compromised by acute symptoms or substance use. Following the provision of consent, participants completed 
interviewer administered baseline questionnaires addressing: socio-demographic characteristics, symptoms of mental illness, substance use, and service use history. Interviewers were trained and supervised in the administration of all scales, including the use of calendar prompts in association with items requesting recall for events over different periods of time. Cash honoraria were provided for the screening questionnaire $(\$ 5.00)$ and the baseline interview (\$25.00).

\section{Measures}

\section{Administrative data}

We examined linked administrative data spanning three provincial government ministries responsible for: health services; justice; and income assistance. Residents of British Columbia are required to enroll with the Provincial Medical Services Plan. Hospital admissions and physician services are reported to the Ministry of Health, along with diagnostic details related to each admission or outpatient visit. The Ministry of Social Development and Social Innovation administers and records financial support to citizens based on demonstration of need, including disability and shelter payments. Details of correctional services (e.g., jail) are maintained by the Ministry of Justice. Mental and behavioural disorders from the International Classification of Diseases (ICD-10) were examined for physician diagnosed mental disorders (excluding psychoactive substance use) associated with hospitalization (F00-09; F20-99).

\section{Availability of data and materials}

Use of these linked data is governed by Information Sharing Agreements between the partnering ministries and the host university. Access to data is subject to police security clearance, restricted to a designated secure off-line environment and other provisions to protect privacy. Additional details concerning these variables are available from the corresponding author, and have been presented elsewhere $[14,26]$.

\section{Self-reported data}

The present analyses include the following sociodemographic variables, which were collected at baseline: gender; age; ethnicity (Aboriginal, White, Other); education; lifetime duration of homelessness; age first homeless; mental disorder status (type, severity, number of diagnoses); substance use disorder and daily substance use. We defined "severe" mental disorders on the basis of current (i.e. past month) psychosis, mood disorder with psychotic features, and hypomanic or manic episode, identified through the MINI. Substance dependence was also identified using the MINI. Timeline follow-back and calendar prompts were used to elicit details of service use associated with health, justice, and social welfare prior to recruitment.

\section{Statistical analysis}

Descriptive statistics (mean and standard deviation for continuous variables; frequency and percentages for categorical variables) were used to characterize the study population. We used independent sample $t$ tests to compare numerical variables (such as age at recruitment and homeless duration) and Pearson's chi square test to compare categorical data (such as gender and ethnicity) between groups.

As a measure of agreement between two sources of records (self-reported vs. administrative data), we reported the simple percent agreement, Cohen's kappa coefficient, and prevalence-adjusted bias-adjusted kappa (PABAK). We first calculated Cohen's kappa, a widely used statistic of agreement for categorical data in clinical research. Although kappa is a more robust measure than simple percent agreement, the magnitude of kappa can be influenced by several factors including the prevalence of the condition of interest and bias, which refers to the extent of disagreement on the proportion of positive cases. Kappa will be underestimated if the prevalence index is high (i.e, prevalence is either very high or very low) and will be overestimated if the bias index is high $[27,28]$. Therefore, we also calculated PABAK to better account for the influence of prevalence and bias. Several recent studies reported PABAK as a measure of agreement [29-32]. We reported $95 \%$ Confidence Intervals for both Cohen's kappa and PABAK.

We used Landis and Koch's [33] classification to evaluate the strength of agreement, which is as follows: slight $(0-0.20)$, fair $(0.21-0.40)$, moderate $(0.41-0.60)$, substantial (0.61-0.80), and almost perfect agreement (0.81-1.0). Because we assessed the agreement between different types of information, we hypothesized a social desirability bias for participants' self-report. To investigate this phenomenon, we conducted McNemar tests of marginal homogeneity to identify any significant systematic difference in terms of disagreement (under-reporting vs. over-reporting) between self-report and administrative records. All reported $p$ values were two sided. IBM SPSS Statistics 22.0 [34] and Stata 13 [35] were used to conduct these analyses.

\section{Results}

The characteristics of participants who consented to accessing administrative data and whose records could be matched $(n=433)$ were compared to the full sample $(n=$ 497) on a number of socio-demographic characteristics (see Table 1). The overall pattern of findings indicates that the eligible sample is broadly representative of the larger cohort. Members of the eligible sample were roughly 41 years of age and were first homeless about 11 years earlier. Nearly three quarters $(74 \%)$ were male, and participants selfidentified as White (54\%), Indigenous (16\%), or Other 
Table 1 Socio-demographic characteristics of 'At home' participants by consent status at enrolment visit

\begin{tabular}{|c|c|c|c|c|}
\hline Variable & $\begin{array}{l}\text { The entire sample }(n=497) \\
n(\%) / \text { mean }(\mathrm{SD})\end{array}$ & $\begin{array}{l}\text { Eligible sample } \mathrm{e}^{\mathrm{a}}(n=433) \\
n(\%) / \text { mean }(\mathrm{SD})\end{array}$ & $\begin{array}{l}\text { Not eligible sample } \\
(n=64) n(\%) / \text { mean (SD) }\end{array}$ & $P$ value \\
\hline Age at randomization (in years) & $40.8(11.0)$ & $40.8(11.0)$ & $41.4(11.0)$ & 0.682 \\
\hline Age of first homelessness (in years) & $30.3(13.3)$ & $30.1(13.4)$ & $31.9(12.6)$ & 0.301 \\
\hline Female gender & $134(27)$ & $112(26)$ & $22(34)$ & 0.165 \\
\hline \multicolumn{5}{|l|}{ Ethnicity } \\
\hline Aboriginals & $77(16)$ & $70(16)$ & $7(11)$ & \multirow[t]{3}{*}{0.054} \\
\hline White & $280(56)$ & $235(54)$ & $45(70)$ & \\
\hline Other & $140(28)$ & $128(30)$ & $12(19)$ & \\
\hline Incomplete High School & $280(57)$ & $247(57)$ & $33(52)$ & 0.376 \\
\hline Single/Never Married & $343(70)$ & $293(68)$ & $50(79)$ & 0.071 \\
\hline Need level (high) & $297(60)$ & $255(59)$ & $42(66)$ & 0.305 \\
\hline Housing first interventions & $297(60)$ & $257(59)$ & $40(63)$ & 0.632 \\
\hline Lifetime duration of homelessness (in months) & $60.2(70.3)$ & $58.3(64.8)$ & $72.9(99.8)$ & 0.124 \\
\hline Longest episode of homelessness (in months) & $30.9(40.1)$ & $30.4(39.5)$ & $34.1(44.4)$ & 0.498 \\
\hline Less severe cluster of mental disorders & $264(53)$ & $235(54)$ & $29(45)$ & 0.180 \\
\hline Severe cluster of mental disorders & $363(73)$ & $311(72)$ & $52(81)$ & 0.113 \\
\hline Suicidality (high) & $87(17)$ & $79(18)$ & $8(12)$ & 0.259 \\
\hline Substance dependence & $288(58)$ & $252(58)$ & $36(56)$ & 0.768 \\
\hline Daily substance use & $143(29)$ & $131(30)$ & $12(19)$ & 0.064 \\
\hline Mental health severity/CSI score (per unit) & $37.2(12.5)$ & $37.4(12.5)$ & $35.8(12.9)$ & 0.371 \\
\hline Chronic Medical Conditions ( 3 or more) & $344(69)$ & $305(70)$ & $39(61)$ & 0.124 \\
\hline Blood-borne Infectious Disease (HIV, Hep. B or C) & $157(32)$ & $139(32)$ & $18(29)$ & 0.603 \\
\hline \multicolumn{5}{|l|}{ Hospitalized for mental illness in last 5 years ${ }^{d}$} \\
\hline Over 6 months & $57(11)$ & $44(10)$ & $13(20)$ & 0.017 \\
\hline Two times or more & $253(51)$ & $215(50)$ & $38(59)$ & 0.146 \\
\hline Hospitalization in last 6 months & $212(43)$ & $187(43)$ & $25(39)$ & 0.533 \\
\hline Any formal charge in last 6 months & $111(23)$ & $101(24)$ & $10(16)$ & 0.172 \\
\hline Jail in last 6 months & $69(14)$ & $62(14)$ & $7(11)$ & 0.465 \\
\hline $\begin{array}{l}\text { Source of income (disability or income assistance) in past } \\
\text { month }\end{array}$ & $469(94)$ & $408(94)$ & $61(95)$ & 0.725 \\
\hline
\end{tabular}

${ }^{\mathrm{a} O u t}$ of 497 participants, 433 provided consent to access to administrative health data and were linkable to health records

${ }^{b}$ Out of 64 participants, 60 didn't consent to access to administrative health data and 4 provided consent, but were unlink-able to health records

${ }^{c} P$ values based on comparisons of characteristics between eligible participants and non-eligible participants in the entire sample

dDidn't know was considered as no

Bold signifies statistical significance

ethnicity (30\%), comprised of Asian, African, Caribbean, Latin American, Middle Eastern, Mixed, or Other categories. The majority of participants met criteria for bipolar disorder, schizophrenia or both ("Severe cluster"; $72 \%$ ) as well as Substance Dependence (58 \%). Table 1 also shows the percentage of the sample that self-reported: having been in hospital for more than 6 months $(10 \%)$ and more than two times $(50 \%)$ in the past 5 years; having been hospitalized (43\%), in jail (14\%), or charged with an offence (24\%) in the last 6 months; and having received either disability or income assistance (94\%) in the past month.

Table 2 presents the simple percent agreement and agreement statistics (Cohen's kappa coefficient and PABAK) between the self-reports and administrative records across specific domains of public service utilization. Based on Cohen's kappa coefficient, five of the six variables examined showed a moderate agreement (jail: kappa $=0.55,95 \%$ confidence interval $(\mathrm{CI})=0.46,0.64$; multiple psychiatric hospitalizations: $\mathrm{kappa}=0.50,95 \% \mathrm{CI}=0.41,0.59$; disability or income assistance: kappa $=0.47,95 \% \mathrm{CI}=0.38$, 0.56 ; ER visit: $\mathrm{kappa}=0.44,95 \% \mathrm{CI}=0.34,0.53$; any hospitalization: kappa $=0.44,95 \% \mathrm{CI}=0.34,0.53)$ and the remaining variable (6 months psychiatric hospitalization) indicated a poor agreement (kappa $=0.21,95 \% \mathrm{CI}=0.12$, 0.30). As expected, some of these variables demonstrated a high prevalence index (6 months psychiatric hospitalization: 
Table 2 Agreement between self-report and administrative records of public service utilization among 'At Home' study participants $\left(n=433^{\mathrm{a}}\right)$

\begin{tabular}{|c|c|c|c|c|c|c|c|c|c|c|c|}
\hline \multirow[t]{2}{*}{ Variables } & \multirow[t]{2}{*}{ Recall period } & \multicolumn{3}{|c|}{ Agreement } & \multicolumn{3}{|c|}{ Disagreement } & \multirow{2}{*}{$\begin{array}{l}\text { Observed kappa } \\
\text { (95\% Cl) }\end{array}$} & \multirow{2}{*}{$\begin{array}{l}\text { Prevalence index, } \\
\text { Bias index }\end{array}$} & \multirow{2}{*}{$\begin{array}{l}\text { PABAK } \\
(95 \% \mathrm{Cl})\end{array}$} & \multirow{2}{*}{$\begin{array}{l}\text { McNemar } \\
\text { test, } p \text { value }\end{array}$} \\
\hline & & Overall & $\begin{array}{l}\text { Both } \\
\text { yes }\end{array}$ & $\begin{array}{l}\text { Both } \\
\text { no }\end{array}$ & Overall & $\begin{array}{l}\text { Over } \\
\text { reporting }\end{array}$ & $\begin{array}{l}\text { Under } \\
\text { reporting }\end{array}$ & & & & \\
\hline $\begin{array}{l}\text { Hospitalized over } \\
\text { six months for } \\
\text { mental illness }\end{array}$ & 5 years & $88 \%$ & $2 \%$ & $86 \%$ & $12 \%$ & $8 \%$ & $4 \%$ & $0.21(0.12,0.30)$ & $0.84,0.05$ & $\begin{array}{l}0.77 \\
(0.71 \\
0.83)\end{array}$ & 0.007 \\
\hline $\begin{array}{l}\text { Hospitalized at least } \\
\text { two times for } \\
\text { mental illness }\end{array}$ & 5 years & $75 \%$ & $30 \%$ & $45 \%$ & $25 \%$ & $19 \%$ & $6 \%$ & $0.50(0.41,0.59)$ & $0.14,0.13$ & $\begin{array}{l}0.50 \\
(0.42 \\
0.58)\end{array}$ & $<0.001$ \\
\hline Any Hospitalization & 6 months & $73 \%$ & $28 \%$ & $45 \%$ & $27 \%$ & $16 \%$ & $11 \%$ & $0.44(0.34,0.53)$ & $0.18,0.04$ & $\begin{array}{l}0.46 \\
(0.37 \\
0.54)\end{array}$ & 0.117 \\
\hline $\begin{array}{l}\text { Any emergency } \\
\text { room visit }{ }^{c}\end{array}$ & 6 months & $73 \%$ & $46 \%$ & $27 \%$ & $27 \%$ & $9 \%$ & $18 \%$ & $0.44(0.34,0.53)$ & $0.19,0.08$ & $\begin{array}{l}0.45 \\
(0.36 \\
0.54)\end{array}$ & 0.002 \\
\hline Jail $^{d}$ & 6 months & $87 \%$ & $11 \%$ & $76 \%$ & $13 \%$ & $4 \%$ & $9 \%$ & $0.55(0.46,0.64)$ & $0.66,0.06$ & $\begin{array}{l}0.74 \\
(0.68 \\
0.81)\end{array}$ & 0.001 \\
\hline $\begin{array}{l}\text { Income source: } \\
\text { disability or income } \\
\text { assistance }\end{array}$ & Past month & $91 \%$ & $86 \%$ & $5 \%$ & $9 \%$ & $8 \%$ & $1 \%$ & $0.47(0.38,0.56)$ & $0.81,0.07$ & $\begin{array}{l}0.82 \\
(0.76 \\
0.87)\end{array}$ & $<0.001$ \\
\hline
\end{tabular}

${ }^{a}$ Out of 497 participants, 433 provided consent to access to administrative data and were linkable to health records

${ }^{b}$ PABAK means prevalence adjusted and bias adjusted kappa

'Restricted to 387 participants

${ }^{\mathrm{d}}$ Analysis was restricted to 428 participants since consent status varied across public service domains

0.84 , disability or income assistance: 0.81 and jail: 0.66 ) associated with the fact that these variables represented either rare (6 months psychiatric hospitalization) or very common conditions (disability or income assistance) in the sample. Bias index was minimal across all variables except for multiple psychiatric hospitalizations. When adjusted for imbalance caused by prevalence differences and bias, kappa values (PABAK) increased substantially for variables addressing 6 month psychiatric hospital separations (PABAK: $0.77 ; 95 \% \mathrm{CI}=0.71,0.83)$, disability or income assistance (PABAK: 0.82; $95 \% \mathrm{CI}=0.76,0.87$ ) and jail (PABAK: 0.74; $95 \% \mathrm{CI}=0.68,0.81)$. Based on PABAK, these variablesshowed substantial (jail and 6 months psychiatric hospitalization) or almost perfect (disability or income assistance) agreement. For other variables, PABAK values showed the same moderate level of agreement as measured by Cohen's kappa coefficient.

Table 2 also presents findings from the McNemar test, which was conducted to identify any systematic difference in terms of disagreement (under-reporting vs. overreporting). Five of the six variables examined resulted in significant disagreement between sources. Participants significantly over-reported having been hospitalized for 6 months or more for a mental illness ( $8 \%$ vs. $4 \%, p=$ 0.007 ) and having been hospitalized at least two times for a mental illness $(19 \%$ vs. $6 \%, p<0.001)$ - both in the previous 5 years. Participants significantly under-reported having been to an emergency department (18\% vs. $9 \% p$ $=0.002)$ or to jail ( $4 \%$ vs. $9 \%, p=0.001)$ within the past 6 months. Finally, participants significantly over-reported having received disability or income assistance in the past month ( $8 \%$ vs. $1 \%, p<0.001)$. There was no significant disagreement between self-report and administrative data with respect to having been hospitalized for any reason in the past 6 months.

\section{Discussion}

Our findings reveal moderate to almost perfect [33] agreement between self-reported service use and corresponding information from administrative sources. To the best of our knowledge, this is the first study to directly compare self-reported and administrative data for multiple domains of public service in a single large sample meeting criteria for chronic homelessness and serious mental illness. These results support the validity of self-report data as the basis for research examining changes in service use and related costs with this subpopulation. In so doing they support the role of people who experience both mental illness and homelessness as participants in the production of knowledge.

Our results hold particular relevance for experimental trials such as those recently implemented in North America [3] and Europe [4], which rely on self-reports to investigate the impact of interventions on service use 
among people who are both homeless and mentally ill. More specifically, the aforementioned trials incorporated items concerning self-reported psychiatric hospitalization in the past 5 years as inclusion criteria - items that our results specifically corroborate.

Previous research among homeless people with chronic alcohol problems employed a similar design to the current study and reported "inadequate" recall over a 3-year period [13]. These findings and those of earlier research among alcoholics [12] may be attributable to the cognitive effects of chronic alcohol exposure [36]. By contrast, our results suggest that individuals who have experienced longstanding homelessness (i.e., 10 years) alongside psychosis or bipolar disorder are nevertheless reliable reporters concerning events in both recent (past month) and distant (5 years) history.

Despite the overall level of agreement between data sources, we identified significant systematic differences in under-reporting versus over-reporting on five out of six variables. Questions related to psychiatric hospitalization during the past 5 years (whether a single long admission or multiple admissions) were associated with significant over-reporting. In contrast, questions related to emergency department visits or jail admissions during the past 6 months were associated with significant underreporting. Finally, having received income assistance in the past month was significantly over-reported, a result that is consistent with previous research on this sub-population [15]. We cannot specify the reasons for disagreement between sources, or why some variables were over-reported while others were under-reported. Nevertheless, the over-reporting of psychiatric hospitalizations in the preceding 5 years may have been due to the difficulty of recalling events over a lengthy period, and may have elicited positive responses corresponding to highly salient events that occurred longer than 5 years in the past. The under-reporting of jail in the preceding 6 months may reflect social desirability as well as stigma associated with incarceration. Homeless individuals may use emergency departments for primary healthcare, and may therefor under-report visits that do not involve emergency complaints. These findings are particularly relevant to research that focuses on specific services (e.g., jail) where systematic over or under-reporting could bias results. They are also relevant to clinical settings where biased responding (e.g., over-reporting of income assistance) may lead to oversights in care planning for patients.

Strengths of our study include: the use of verified administrative data; multiple categories of service; administrative records spanning a long-duration (i.e., up to 5 years); pre-testing of interview questions [25]; and use of calendar aids to strengthen recall. Limitations of our study include: unaccounted for errors associated with administrative records (e.g., coding errors); potential use of aliases when receiving care; and unrecorded events due to not having identification.

\section{Conclusions}

Our study found that individuals who experience chronic homelessness and serious mental illness are accurate historians regarding their encounters with public services. We observed high levels of agreement between administrative records and self-report for healthcare, jail, and welfare support spanning periods of time from 1 month to 5 years. Significant over-reporting (e.g., psychiatric hospitalization) and under-reporting (e.g., jail) was specific to individual service areas and warrants caution in studies that focus on these particular domains.

\section{Competing interests}

The authors declare that they have no competing interests.

\section{Authors' contributions}

JS led the research project, jointly conceived the study, and drafted the main manuscript. AM jointly conceived the study, led the analysis of data, and drafted sections of the manuscript. LC collected data for the study and drafted sections of the manuscript. SR collected data for the study and drafted sections of the manuscript. AR collected data for the study and drafted sections of the manuscript. MP collected data for the study and drafted sections of the manuscript. All authors read and approved the final version of the manuscript.

\section{Acknowledgements}

This study was funded by a grant from the Mental Health Commission of Canada to Simon Fraser University. The authors gratefully acknowledge the study participants and community agencies that collaborated in this research.

Received: 8 October 2015 Accepted: 21 February 2016

Published online: 25 February 2016

\section{References}

1. Mechanic D. Seizing the opportunities under the Affordable Care Act for transforming the mental and behavioral health system. Health Aff. 2012;31(2):376-82

2. Gaebel W, Zielasek J. Homeless and mentally ill - a mental healthcare challenge for Europe. Acta Psychiatr Scan. 2015;131(4):236-8.

3. Goering PN, Streiner DL, Adair C, et al. The At Home/Chez Soi trial protocol: a pragmatic, multi-site, randomized controlled trial of a housing first intervention for homeless individuals with mental illness in five Canadian cities. BMJ Open. 2011;1:e000323.

4. Tinland A, Fortanier C, Girard V, et al. Evaluation of the housing first program in patients with severe mental disorders in France: study protocol for a randomized controlled trial. Trials. 2013;14:309.

5. Johnson G, Parkinson S, Parsell C. Policy shift or program drift? Implementing Housing First in Australia, AHURI Final Report No. 184 Australian Housing and Urban Research Institute, Melbourne. 2012.

6. Wang PS, Lane M, Olfson M, Pincus HA, Wells KB, Kessler RC. Twelve-month use of mental health services in the United States: results from the national comorbidity survey replication. Arch Gen Psychiatry. 2005;62(6):629-40.

7. Druss BG, Rosenheck RA. Patterns of health care costs associated with depression and substance abuse in a national sample. Psychiatr Serv. 1999:50(2):214-8.

8. Goldberg RW, Seybolt DC, Lehman A. Reliable self-report of health services use by individuals with serious mental illness. Psychiatr Serv. 2002;53(7):879-81

9. Gelberg L, Siecke N. Accuracy of homeless adults' self-report. Med Care. 1997;35(3):287-90. 
10. Caslyn RJ, Morse GA, Kinkenberg WD, Trusty ML. Reliability and validity of self-report data of homeless mentally ill individuals. Eval Program Plann. 1997;20(1):47-54.

11. Metraux S, Stino M, Culhane DP. Validation of self-reported veteran status among two sheltered homeless populations. Public Health Rep. 2014;129(1):73-7.

12. Annis HM. Self-report reliability of skid row alcoholics. Br J Psychiatry. 1979;134:459-65.

13. Clifasefi SL, Collins SE, Tanzer K, Burlington B, Hoang SE, Larimer ME. Agreement between se;f-report and archival public service utilization data among chronically homeless individuals with severe alcohol problems. J Community Psychol. 2011;39(6):631-44.

14. Somers JM, Patterson ML, Moniruzzaman A, et al. Vancouver at home: pragmatic randomized trials investigating housing first for homeless and mentally ill adults. Trials. 2013;14:365.

15. Rosen MI, McMahon TJ, Rosenheck RA. Homeless people whose self-reported SSI/DI status is inconsistent with social security administration records. Soc Secur Bull. 2007;67(1):53-62.

16. Bhandari A, Wagner T. Self-reported utilization of health care services: improving measurement and accuracy. Med Care Res Rev. 2006;63:217-35.

17. Kertesz SG, Crouch K, Milby JB, Cusimano RE, Schumacher JE. Housing first for homeless persons with active addiction: are we overreaching? Milbank Q. 2009;87(2):495-534.

18. Monahan J, Bonnie RJ, Applebaum PS, Hyde PS, Steadman HJ, Swartz MS. Mandated community treatment: beyond outpatient commitment. Psychiatr Serv. 2001;52(9):1198-205.

19. Weber EJ, Showstack JA, Hunt KA, et al. Are the uninsured responsible for the increase in emergency department visits in the United States? Ann Emerg Med. 2008; doi:10.1016/jannemergmed. 2008.01.327

20. Frank JW, Wang EA, Nunez-Smith M, Comfort M. Discrimination based on criminal record and healthcare utilization among men recently released from prison: a descriptive study. Health Justice. 2014; doi:10. 1186/2194-7899-2-6.

21. McKee M, Dixon J, Chenet L. Making routine data adequate to support clinical audit. BMJ. 1994;(309):1246-1247

22. Groene $\mathrm{O}$, Kristensen $\mathrm{S}$, Arah $\mathrm{OA}$, et al. Feasibility of using administrative data to compare hospital performance in the EU. Int J Qual Health Care. 2014;26(S1):108-15.

23. Andersen JS, Olivarius N, Krasnik A. The Danish National Health Service register. Scand J Pub Health. 2011;39(7):34-7.

24. Sheehan DV, Lecrubier $Y$, Sheehan $\mathrm{KH}$, et al. The mini-international neuropsychiatric interview (MINI): the development and validation of a structured diagnostic psychiatric interview for DSM-IV and ICD- 10. J Clin Psychiatr. 1998;59:22-33.

25. Adair CE, Holland AC, Patterson ML, et al. Cognitive interviewing methods for questionnaire pre-testing in homeless persons with mental disorders. J Urban Health. 2012;89:36-52.

26. Rezansoff SN, Moniruzzaman A, Gress C, Somers JM. Psychiatric diagnoses and multiyear criminal recidivism in a Canadian provincial offender population. Psychol Public Policy Law. 2013;19:443-53.

27. Byrt T, Bishop J, Carlin JB. Bias, prevalence and kappa. J Clin Epidemiol. 1993:46:423-9.

28. Sim J, Wright CC. The kappa statistic in reliability studies: use, interpretation, and sample size requirements. Phys Ther. 2005;85:257-68.

29. Marrie RA, Fisk JD, Yu BN, et al. The CIHR team in the epidemiology and impact of comorbidity on multiple sclerosis: mental comorbidity and multiple sclerosis: validating administrative data to support population-based surveillance. BMC Neurol. 2013;13(1):16. doi:10.1186/1471-2377-13-16.

30. Cibere J, Thorne A, Bellamy N, et al. Reliability of the hip examination in osteoarthritis: effect of standardization. Arthritis Rheum. 2008;59:373-81.

31. Girianelli VR, Santos Thuler LC. Evaluation of agreement between conventional and liquid-based cytology in cervical cancer early detection based on analysis of 2,091 smears: experiences at the Brazilian National Cancer Institute. Diagn Cytopathol. 2007;35:545-9.

32. Steel Z, Silove D, Chey T, Bauman A, Phan T. Mental disorders, disability and health service use amongst Vietnamese refugees and the host Australian population. Acta Psychiatr Scand. 2005;111:300-9.

33. Landis JR, Koch GG. The measurement of observer agreement for categorical data. Biometrics. 1977;33:159-74.
34. Corp IBM. Released. IBM SPSS statistics for windows, version 22.0. IBM Corp.: Armonk, NY; 2013.

35. StataCorp. Stata statistical software: release 13. College Station, TX: StataCorp LP; 2013.

36. Stavro K, Pelletier J, Potvin S. Widespread and sustained cognitive deficits in alcoholism: a meta-analysis. Addict Biol. 2014;18(2):203-13.

\section{Submit your next manuscript to BioMed Central and we will help you at every step:}

- We accept pre-submission inquiries

- Our selector tool helps you to find the most relevant journal

- We provide round the clock customer support

- Convenient online submission

- Thorough peer review

- Inclusion in PubMed and all major indexing services

- Maximum visibility for your research

Submit your manuscript at www.biomedcentral.com/submit
) Biomed Central 